\title{
Ensino e prática de um jornalismo em transformação
}

Por Lívia de Souza

Vieira

Doutoranda do POSJOR/UFSC e docente nos cursos de Jornalismo e Publicidade e Propaganda do

Bom Jesus/IELUSC

${ }^{1}$ Uma versão parcial desta entrevista foi publicada no site do ObjETHOS, grupo de pesquisa e extensão do POSJOR/UFSC.

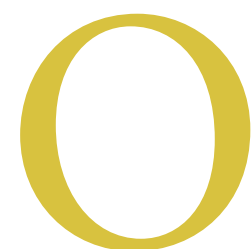

jornalismo de dados é a grande paixão do professor Paul Bradshaw, e é por meio dele que seu trabalho é reconhecido em diversos países. Além de coordenador do mestrado em Jornalismo Móvel e Multiplataforma e do recém-lançado mestrado em Jornalismo de Dados na Birmingham City University (BCU - Inglaterra), Bradshaw costuma se apresentar como jornalista online e blogueiro. Nesta entrevista, ele fala sobre metodologias de ensino do jornalismo, aproximação entre academia e mercado, newsmaking e métricas de audiência. Além disso, dá exemplos de reportagens que desenvolve na Unidade de Dados da $B B C$, onde é consultor.

As perguntas a seguir são resultado de minha observação pessoal e aprendizado no período de doutorado-sanduíche, no qual tive Paul Bradshaw como meu supervisor. O bate-papo regado a café aconteceu no estúdio de rádio da BCU, em março de $2017^{1}$.

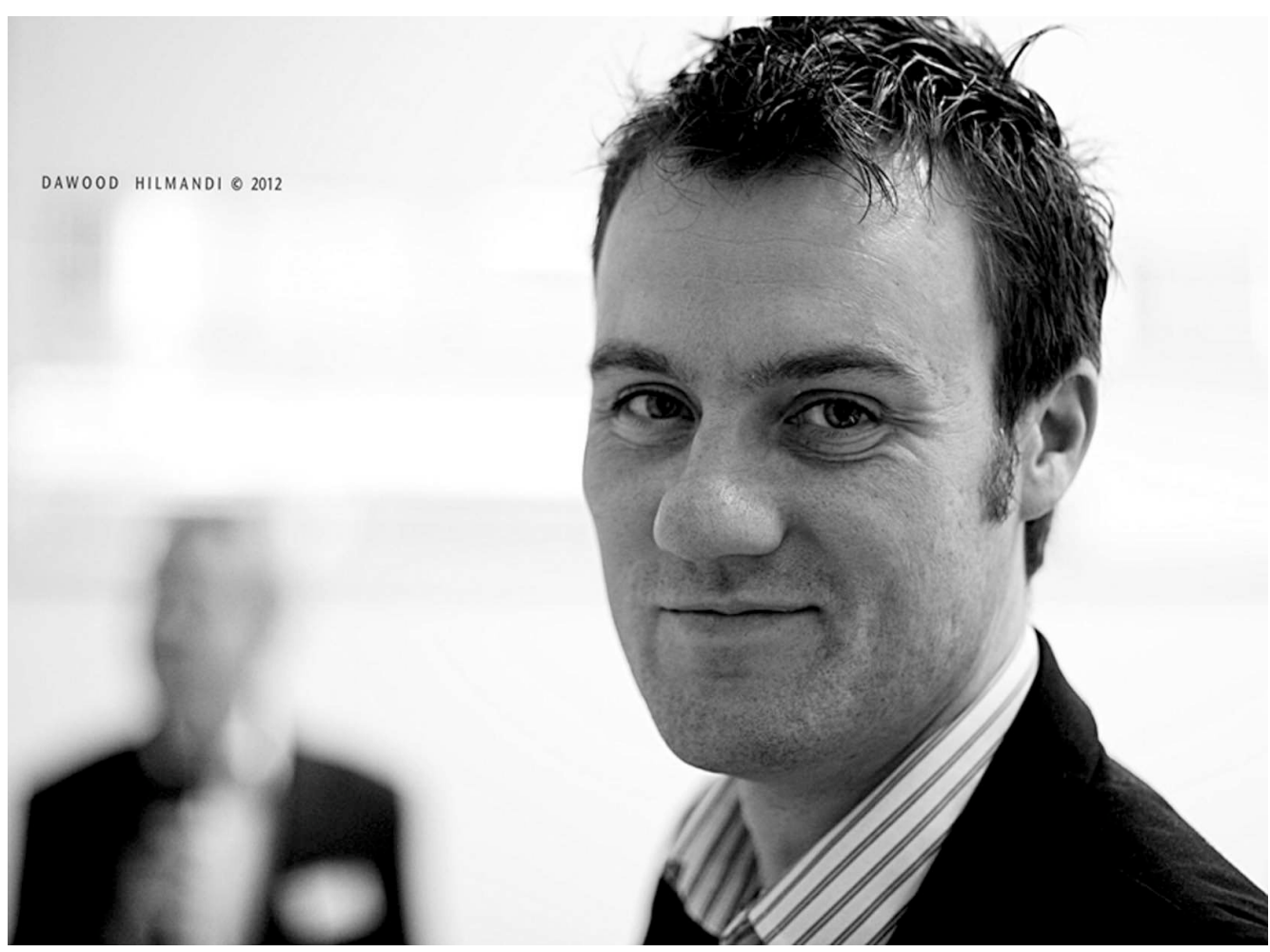

EJM - Observei que o senhor tem uma forma diferente de ensinar jornalismo. Pode descrever brevemente a metodologia que utiliza em sala de aula? 
PAUL BRADSHAW - Essa metodologia é chamada Flipped Classroom, na qual os alunos trabalham em um projeto, trazem esse projeto para a sala de aula e isso forma a base do ensino. No modo tradicional, o professor fica em pé na sua frente dizendo como você deve fazer e todos tentam acertar na primeira vez. Penso que uma das vantagens do método Flipped é que você pede aos alunos para identificar onde está a força de cada um. Em primeiro lugar, os estudantes podem olhar os trabalhos uns dos outros e aprender com eles, o que penso ser realmente muito importante, pois não se trata apenas de aprender com o professor. Em segundo lugar, eles se tornam mais críticos e preocupados com seus próprios processos. Nem sempre funciona perfeitamente, pois você confia que os alunos têm independência e, em alguns casos, principalmente com os alunos de graduação, se eles não fazem as tarefas, vão tentar não vir para a classe, porque sentem que de alguma forma falharam. Penso que uma parte difícil é essa mudança de mentalidade, a tentativa de fazer os alunos perceberem que não se espera que eles acertem na primeira vez. Errar é uma parte muito importante do aprendizado e eles não precisam ficar envergonhados por isso. Mais amplamente, o ambiente informacional do ensino tem mudado, assim como o ambiente do jornalismo. No ensino de 20 anos atrás, se você era um estudante, tinha acesso às aulas e à biblioteca e era isso. Então, você tinha leituras e obtinha informação por meio das aulas. Agora, é claro, é diferente! Você tem acesso a todo um mundo de informação pela internet. Particularmente, creio que não é eficiente repetir o modelo de 20 anos atrás, ainda mais porque ele torna os alunos menos independentes. Uma habilidade importante hoje, mais do que há 20 anos, é a de encontrar informação e estar atualizado com o que está acontecendo. Outro elemento significativo da minha maneira de ensinar é desenvolver habilidades de um aprendizado independente e engajamento com o que chamo de comunidades de prática.

\section{EJM - Pode explicar como isso funciona?}

PAUL BRADSHAW - No módulo do mestrado que estou ministrando no momento, a primeira avaliação se chama "comunidades de prática" e a ideia é que os alunos desenvolvam habilidades específicas e façam isso de modo que contribua com a comunidade profissional [de jornalistas]. Então, se você vai ser um jornalista de dados, há dois caminhos: você senta na sala de aula e aprende o conteúdo em dez semanas - este é o modo antigo; ou - o que penso ser a melhor forma - você começa a se engajar com a indústria jornalística, fazer contatos e entrevistar pessoas do campo. Desde o início, você pode experimentar e compartilhar seus sucessos e fracassos, pode se envolver em discussões online. Assim, é preciso saber onde as pessoas do mercado estão, construir relacionamentos. Trata-se de um tipo de ensino que permite e encoraja os alunos a se conectarem com a ampla rede de informação ao seu redor.

\section{EJM - Percebo que sua preocupação, além de ensinar as diversas ferramentas, é desenvolver as habilidades dos alunos...}

PAUL BRADSHAW - Sim, é muito importante que cada estudante tenha um perfil distinto. E essa é uma diferença do modelo tradicional de ensino, no qual você ensina as mesmas habilidades para 15 pessoas, por exemplo. Esse tipo de estandardização faz sentido quando a indústria está estandardizada. Talvez daqui a 20 ou 30 anos o jornalismo de dados, por exemplo, esteja suficientemente estandardizado, e 
será o caso de os alunos aprenderem todos a mesma coisa. Mas, no momento, penso que a adaptabilidade é realmente importante, assim como se diferenciar. Tento ajudar meus alunos a identificar no que eles querem focar e apoiá-los.

EJM - Outro ponto muito importante que observei é a aproximação entre academia e mercado. $O$ senhor sempre convida os estudantes a participarem de eventos nas grandes redações e também traz fontes especializadas para conversar com eles durante as aulas. Por que faz esse movimento?

PAUL BRADSHAW - Faço isso porque essa é exatamente a ideia das comunidades de prática. Quando alguém me manda uma mensagem no twitter falando sobre alguma iniciativa, por exemplo, eu digo "por que você não fala sobre isso com meus alunos e comigo ao mesmo tempo?". E o mesmo acontece quando sou convidado a palestrar em algum veículo jornalístico: eu digo "posso falar se meus alunos também puderem ir". Trata-se de expor os estudantes a diferentes partes da mídia, mas não é só a mídia, mas também fontes, pesquisadores. Existe muito mais além da mídia do que se pode imaginar.

\section{EJM - Que tipo de perfil profissional o senhor considera que o jornalista deve ter hoje?}

PAUL BRADSHAW - É realmente difícil dizer, porque há tantas mudanças acontecendo em diferentes lugares e de diferentes formas... Penso que há certa vantagem se o jornalista tem um entendimento amplo dessas possibilidades, além de ter a mente aberta. Tenho visto diversos cenários no jornalismo, boas iniciativas no twitter, em blogs, com vídeos em formato vertical, com listas. Hoje pela manhã, vi o jornal The Telegraph fazendo uma lista das 20 vezes em que os políticos conservadores tuitaram que não aumentariam os impostos. Esse é um exemplo clássico em que uma organização tradicional escreve sobre um assunto duro realmente engajando, utilizando listas de modo a tornar o tema mais acessível. É por isso que estou muito interessado em coisas como: as pessoas estão assistindo aos vídeos verticais? O que há de errado com eles? As pessoas estão lendo listas? Ou seja, como o jornalismo pode engajar pessoas em histórias que de outra forma não se engajariam? Assim, não creio que há um perfil específico, mas ter a mente aberta e pensar de forma estratégica, pois hoje os jornalistas precisam fazer escolhas que os publishers costumavam fazer (quando, como e onde publicar). Além disso, é preciso pensar mais criticamente sobre a informação. Então, os jornalistas precisam ser melhores agora do que costumavam ser.

EJM - Seu blog é referência no campo do jornalismo. Como ele surgiu e de que forma o administra?

PAUL BRADSHAW - O blog foi criado em 2004, há 13 anos. Na época, eu era professor de jornalismo online e pensava que era importante experimentar esse novo formato de publicação e essa plataforma. Naquele momento não era sobre jornalismo, era algo apenas pessoal. Então, depois de seis meses, comecei a pensar que poderia postar mais frequentemente. Foi quando migrei para o WordPress e mudei o nome. Em 2006 ou 2007, talvez, lembro que pessoas como Martin Stable 
(que na época estava na Press Gazette) estavam comentando no blog. Até aquele momento o blog era realmente algo para mim, mas então comecei a perceber que estava se transformando em uma comunidade. Hoje, o número de acessos depende da frequência com que posto, mas é algo em torno de 50 mil visualizações de página por mês.

\section{EJM - Falando sobre jornalismo de dados, que é a sua área de maior interesse, é importante encontrar as histórias humanas nos dados? Por quê?}

PAUL BRADSHAW - Sim, penso que o bom jornalismo deve ter uma forte base factual e o lado humano, uma combinação desses dois. $O$ jornalismo de dados começa de um ponto de base factual, assumindo que o dado é factual. É fácil pensar que, como um jornalista de dados, você costuma se interessar mais por isso do que os outros. Mas é também importante dizer como isso se desenvolve na vida cotidiana das pessoas. Dados podem complementar histórias humanas ou podem ser o coração da matéria. Depende apenas de como você se depara com a história. Numa redação não guiada por dados, as pautas vêm de releases, anúncios governamentais, coletivas, etc. Numa redação guiada por dados, sua pauta é principalmente os dados e então você começa a olhar para as histórias humanas, trata-se apenas da ordem como as coisas acontecem.

\section{EJM - Pode exemplificar?}

PAUL BRADSHAW - Um exemplo atual foi a história de uma pessoa que trabalha numa empresa de entregas. Se ela fica doente, tem que pagar 150 libras caso não arranje outra pessoa para cobri-la. Então, isso era apenas uma história. Como jornalista, vou pensar: agora precisamos estabelecer a amplitude disso, quão grande é esse problema. Ele afeta outras empresas? Essa empresa específica, se ela tem um grande lucro, não precisa financeiramente pedir para o funcionário pagar esse valor. Vou dar outro exemplo da Unidade de Dados da BBC: a esposa de um dos jornalistas, quando estava grávida, foi convidada a ter o bebê no que eles chamam de Midwife-led Unit. Não é necessário que o parto ocorra num hospital, então, se não é uma gravidez de risco, essa é a melhor opção. Mas ele começou a pensar: bem, quantas vezes uma paciente teve que ser transferida dessa unidade para um hospital porque algo de errado aconteceu? Isso é um problema? E aí entram os dados.

\section{EJM - Sobre as mudanças no jornalismo, especificamente no newsmaking, o senhor acha que a produção jornalística se transformou após o desenvolvi- mento dos analytics e dos dados sobre a audiência?}

PAUL BRADSHAW - Sim, absolutamente. Penso que essa é uma das maiores mudanças no jornalismo, e de novo é outro exemplo no qual jornalistas têm que tomar decisões que antes os publishers tomavam. Mas em todos os cenários há pessoas que se levantam pra dizer "isso é terrível, está arruinando o jornalismo" ou "isso é o futuro do jornalismo". Eu estarei sempre em alguma posição no meio, que diz que há muitos pontos positivos e possibilidades, e que há alguns pontos negativos. Um dos pontos positivos é o fato de que os jornalistas estão muito mais responsáveis no contato com a audiência do que jamais foram. E isso aconteceu antes do crescimento dos analytics, fiz uma pesquisa sobre blogs em 2009 e fiquei bastante surpreso 
em como blogueiros mudaram o comportamento quando os leitores começaram a poder comentar e entrar em contato com eles. Então, os analytics são uma espécie de extensão disso. Outro exemplo da Unidade de Dados da $B B C$ : nós fizemos uma matéria sobre o preço das casas que as pessoas podem comprar pelo programa de governo Help to Buy. Essa reportagem teve mais de um milhão de acessos! Baseado nisso, a equipe começou a pensar diferente sobre o que é o interesse do público, nos fez pensar que as pessoas se importam com matérias sobre finanças pessoais. Você não está escrevendo para seus pares, mas para uma audiência. Por décadas as organizações jornalísticas têm lutado para engajar os jovens, e o BuzzFeed, que é extremamente guiado pelas métricas, encontrou o caminho para engajar uma audiência que tem sido por um longo tempo excluída da maneira tradicional de reportar notícias - e eles não ganharam crédito suficiente por isso. Por outro lado, isso pode ser usado de uma forma ruim e me frusta ver tão pouca literatura sobre analytics. O relatório do Tow Center sobre analytics no The New York Times e Gawker é muito interessante porque mostra essa conexão entre o que os editores pensavam que acontecia quando os jornalistas tinham acesso ao analytics e como eles de fato os utilizavam. Existe, então, uma responsabilidade de treinar melhor os jornalistas para utilizarem o analytics de maneira mais crítica.

\section{EJM - O senhor acha que estamos caminhando de uma cultura do clique para uma cultura mais qualitativa com relação às métricas?}

PAUL BRADSHAW - Vagarosamente. O entendimento está se sofisticando, assim como muitas habilidades estão também ficando mais sofisticadas.

\section{EJM - Nos últimos anos, temos ouvido muito a respeito da crise no jornalismo (no modelo de negócios, credibilidade e confiança). O senhor concorda com isso?}

PAUL BRADSHAW - Penso que há uma crise acontecendo, mas há também uma revolução. Há uma transformação no jornalismo, o que é uma das coisas mais positivas. Se olharmos ao longo disso, há um período de invenção e criatividade tremendo. Sobre engajamento de novas audiências, há novos publishers falando para audiências que não eram servidas anteriormente, hoje é possível se comunicar com pequenas audiências que antes eram economicamente inviáveis. Então, há muitas coisas boas. Há uma crise para as indústrias tradicionais de notícias e o modelo de negócios é uma parte grande disso. É importante destacar que muitas pessoas, quando falam da crise, geralmente se referem apenas à indústria de notícias tradicional, ao corte de empregos. Mas há tantas partes novas na indústria de notícias que não são contadas nessas queixas. Há dezenas de empregos sendo criados. Se nós pudéssemos voltar 20 anos no tempo e decidir por não ter a internet, eu não faria isso. Eu realmente acredito que, em 20, 30 anos as coisas estarão suficientemente estabelecidas. É interessante ver como Facebook, Google e outras organizações de mídias sociais estão fazendo muito dinheiro com conteúdo, e não com notícias. Realmente me perturba quando os veículos jornalísticos dizem que o Google está fazendo dinheiro com o conteúdo deles. Não, eles não estão, vocês são insignificantes. Mas Google e Facebook estão investindo dinheiro para apoiar organizações de notícias, novos modelos, e isso é muito interessante. Estamos caminhando para um ponto onde há diversas formas de jornalismo, que são sustentadas de diferentes maneiras. Não se trata somente das grandes empresas, é algo mais 
distribuído, granular, mas também nem tudo é bom. A grande questão é: como podemos preservar as coisas boas?

EJM - O senhor escreveu diversos livros e agora está trabalhando em mais alguns. Pode falar sobre eles?

PAUL BRADSHAW - Acabei de finalizar a segunda edição do Online Journalism Handbook, que deve ser publicado ainda em 2017. Ele será 50\% maior que o primeiro, e foi muito interessante escrevê-lo. Também atualizei o Scrapping for Journalists. Vou ainda começar a trabalhar num livro sobre jornalismo em multiplataformas e quero escrever outro sobre java script para produtores de conteúdo. 